\title{
Xamanismo e neoxamanismo no circuito do consumo ritual das medicinas da floresta
}

Ritualistic shamanism and neoshamanism in the forest medicines consumption circuit

\author{
Saulo Conde Fernandes * \\ * Secretaria Municipal de Educação - Campo Grande, MS, Brasil \\ saulodahistoria@gmail.com
}




\title{
Resumo
}

A partir de dados construídos em alguns anos de trabalho de campo entre grupos ayahuasqueiros, assim como de um consistente estado da arte, proponho uma tentativa de classificação acerca de algumas modalidades de xamanismo/neoxamanismo no circuito do consumo ritual das substâncias psicoativas conhecidas como medicinas da floresta. Apresento o Santo Daime (religião ayahuasqueira brasileira), o xamanismo urbano (ou neoxamanismo) e o xamanismo pano (tronco linguístico que engloba diversas etnias localizadas especialmente na floresta amazônica) como modelos de xamanismos ayahuasqueiros, os quais se articulam através de redes de alianças, e organizam circuitos pelos quais circulam indivíduos, substâncias, saberes e tradições. Nesse território de experiências performáticas e (re)invenção de tradições, os agentes depositam no consumo ritual das medicinas da floresta a centralidade de suas cosmogonias.

Palavras-chave: xamanismo; medicinas da floresta; circuito; tradição.

\begin{abstract}
Starting from data gathered in several years of field research among the traditional Ayahuasca drinkers, as also setting awareness, I propose an effort to classify a few modalities of the ritualistic Ayahuascan shamanistic/neoshamanistic consumption of the psychoactive substances known as forest medicines. In order to archive this goal, I introduce the Santo Daime (Brazilian Ayahuascan Religion), the urban shamanism (or neoshamanism) and the Pano shamanism (linguistic family that includes several ethnics groups located particularly in the amazonic forest) as models of Ayahuascan shamanism, which articulate themselves through alliances, and work on circuits in which individuals, substances, knowledges and traditions can move Freely. In this domain, where performatic experiences and traditions (re)inventions are made, its protagonists place in ritualistic consumption the centrality of their Cosmogenesis.
\end{abstract}

Keywords: shamanism; forest medicines; circuit; tradition. 


\section{Introdução}

Um dos pontos-chave do presente texto é a bebida psicoativa ayahuasca, ${ }^{1}$ utilizada milenarmente por diversas etnias indígenas da porção ocidental da floresta amazônica, e que hoje se configura como o elemento ritualístico principal de diversas religiões e novas espiritualidades urbanas. É obtida através da decocção do cipó Banisteriopsis caapi, conhecido popularmente como jagube ou mariri, e da folha Psychotria viridis, conhecida como rainha ou chacrona. ${ }^{2}$ A bebida, que em quéchua significa "cipó das almas",

também recebe muitos outros nomes de origem indígena, em suas regiões de uso, como: "caapi", "yajé", "pildé”, "dapa”, "kamaranpi". Entre caboclos da região brasileira, é também conhecido como "cipó", "vegetal", "daime" e corruptelas da palavra "ayahuasca”, como: "aosca”, "huasca”, "uasca”, "hoasca” e "oasca”. (Moreira; MacRae, 2011, p. 87).

Luiz Eduardo Luna (1986) apresenta uma lista de 72 grupos indígenas da região amazônica que fazem uso da ayahuasca e denota algumas características do uso ameríndio da bebida: entrar em contato com o mundo dos espíritos; conhecer profundamente o meio ambiente; diagnosticar e curar doenças; adivinhação e caça; enfim, é parte da composição cultural, mitológica, religiosa, artística de diversas etnias. Nos usos contemporâneos da ayahuasca, seja em contextos indígenas ou não indígenas, rurais ou urbanos, sobressai o tema da cura, que era um dos elementos principais do uso ancestral indígena, mas que estava entre algumas outras atribuições.

1 Entre as substâncias denominadas de medicinas da floresta no circuito xamânico contemporâneo, a ayahuasca é considerada pelos adeptos como a mais importante. Por isso considero essa bebida como um dos pontos-chave deste texto.

2 Beatriz Labate (2005, p. 404) resume a peculiaridade química resultante do processo de mistura dessas duas plantas: "O arbusto Psychotria viridis contém um princípio ativo, a DMT (N, N-Dimetiltriptamina). Tal princípio possui uma semelhança estrutural com a serotonina, um importante neurotransmissor do sistema nervoso central. Quando administrada por via oral, a DMT é decomposta pela monoaminoxidase (MAO), tornando-se inativa. O cipó contém alcalóides betacarbolínicos: a harmina, a harmalina e a tetrahidroharmina. Estes alcalóides inibem a atuação da enzima de MAO, o que evita que esta inative a DMT contida na folha. Assim, a interação entre esses alcalóides e a DMT permite que a bebida atue sobre o corpo humano, produzindo alterações nele [....." 
Dos diversos contextos atuais de consumo ritual da ayahuasca, apresento o santo daime (religião ayahuasqueira brasileira), o xamanismo urbano (ou neoxamanismo) e o xamanismo pano (tronco linguístico que engloba diversas etnias localizadas especialmente na floresta amazônica), como exemplos de xamanismos ayahuasqueiros que se articulam através de redes de alianças, e organizam circuitos pelos quais circulam indivíduos, substâncias, saberes e tradições. Nesse território de experiências performáticas e (re)invenção de tradições e rituais, sobressaem-se o consumo ritual de substâncias psicoativas e/ou terapêuticas, denominados pelos adeptos indígenas e não indígenas de medicinas da floresta, ${ }^{3}$ que do complexo cultural pano passou a ser utilizada nos contextos urbanos do neoxamanismo e do Santo Daime.

$\mathrm{Na}$ fronteira entre adepto $\mathrm{e}^{4}$ "antropólogo ayahuasqueiro" - categoria proposta por Beatriz Labate (2004, p. 53) que designaria uma forma de "permanecer ligado ao fenômeno a partir de dentro mas também de fora" -, percorri caminhos no circuito urbano da ayahuasca, participei ativamente da produção e realização de eventos daimistas e xamânicos, passei por experiências performáticas em rituais com consumo de psicoativos, fiz contatos e amizades, e engendrei um olhar antropológico para muitas dessas vivências dos últimos anos. Desde 2009 realizo pesquisa sistemática entre grupos ayahuasqueiros de Mato Grosso do Sul e São Paulo, e eventualmente em Santa Catarina e Bahia. ${ }^{5}$

Aderindo à antropologia simbólica (Langdon, 1996, p. 23-24), creio que a hermenêutica envolve o trabalho antropológico; a interpretação do significado é inerente à vida humana (Soares, 1994). O texto antropológico é uma interpretação (do pesquisador) de interpretações (dos pesquisados), sendo ficção, no sentido de algo construído (Geertz, 2008). O trabalho do antropólogo - olhar, ouvir, escrever (Cardoso de Oliveira, 2006) - assume características peculiares quando aplicadas ao estudo das "sociedades complexas" (no caso em questão, as redes de relações daimistas e [neo]xamânicas): a observação direta

3 Adiante descrevo o que seriam as medicinas da floresta.

4 Sou fardado (o termo equivale a filiado) na religião do Santo Daime desde 2009, e participo eventualmente de rituais xamânicos com indígenas e não indígenas.

5 Apesar da minha pesquisa de mestrado ter tido como foco a diversidade das religiões afro-brasileiras (Fernandes, 2015), fui paralelamente construindo dados no âmbito das religiões ayahuasqueiras, e este será, provavelmente, o tema geral de minha pesquisa de doutorado. 
e contínua se converte em observação flutuante, isto é, o observador está sempre em situação de pesquisa, sua atenção podendo ser exigida a qualquer instante (Goldman, 1999, p. 115). Nesse sentido, meu processo de construção de dados, e análise, reflexão e interpretação destes, aconteceu de forma caótica, sendo que a qualquer momento eu poderia estar pensando e indo a frente com a pesquisa, inclusive nos momentos em que eu estava "na força", isto é, no efeito psicoativo da bebida, que pode se manifestar de inúmeras formas. ${ }^{6}$

\section{Matrizes do circuito xamânico contemporâneo}

\section{Santo Daime}

O Santo Daime é uma religião brasileira sincrética (Dias Jr., 1992; Guimarães, 1992; MacRae, 1992), que foi gradativamente sendo estruturada a partir de 1930 por Raimundo Irineu Serra, um típico líder carismático (Weber, 1991) que ficou conhecido como Mestre Irineu. Para os adeptos, Mestre Irineu teria recebido da própria Virgem da Conceição (denominada por ele de Rainha da Floresta) a missão de recriar no mundo uma santa doutrina, que seria a religião daimista. O encontro de Irineu Serra com a Virgem, após a ingestão da ayahuasca, seria o mito fundador da religião (Goulart, 1996). Conforme indica Groisman (1999, p. 101, grifo do autor), Irineu teria transformado "[...] simbolicamente a ayahuasca em Daime, de certa forma domesticando, convertendo e sacralizando a bebida".

Alguns autores assinalam a iniciação (que envolveu dietas alimentares e interditos sexuais) de Mestre Irineu, citando o xamanismo amazônico e o vegetalismo (Antunes, 2011; Couto, 1989; MacRae, 1992). Há relevantes indícios de que Irineu teria sido iniciado com xamãs de uma ou mais etnias da família linguística pano,

6 Labate (2004, p. 33-63) discute problemáticas relacionadas ao trabalho do antropólogo que estuda psicoativos, e demonstra as possibilidades e os limites que essa escolha metodológica ("beber a ayahuasca" com os grupos estudados) implica. Interessante ressaltar que, no prefácio dessa obra, o consagrado antropólogo e professor da Unicamp Mauro Almeida (2004) comenta que o "cipó" (outro nome pra ayahuasca) lhe deu conselhos acadêmicos importantes para que terminasse uma tese de doutorado iniciada na Inglaterra. Mesmo não tendo religião, Almeida afirma que participava com empatia de rituais com o cipó e ainda recebia conselhos deste. 
mesmo não sendo possível precisar qual ou quais ${ }^{7}$ (Fernandes, no prelo). Mesmo sofrendo perseguições ocasionais por parte do governo ou da Igreja Católica, Mestre Irineu conquistou aura carismática, contando com a amizade de pessoas influentes de sua época e local, inclusive políticos acrianos (MacRae, 1992, p. 65), assim como conquistou também fama de grande curador na região. Até sua morte, em 1971, a religião daimista restringia-se à sua comunidade (Alto Santo).

O Santo Daime passou "de uma comunidade fortemente regionalista para um grupo religioso heterogêneo, transnacional e inserido na dinâmica do campo religioso moderno" (Assis; Labate, 2014, p. 12) a partir de uma vertente fundada por Sebastião Mota de Melo, líder religioso e comunitário que se tornou um dos seguidores de Mestre Irineu nos últimos anos de vida deste. Após contato com Mestre Irineu, passou a produzir a bebida e a frequentar o Alto Santo com a família, amigos e agregados, e foi transformando sua comunidade, a Colônia Cinco Mil, em uma igreja daimista. Três anos após a morte de Mestre Irineu, em 1974, se efetiva um rompimento de Padrinho Sebastião com a diretoria do Alto Santo, e uma parcela significativa dos membros acompanha o líder espiritual até a Colônia Cinco Mil (MacRae, 1992, p. 72) - Couto (1989, p. 94) crê que foram 70\% dos membros, enquanto que Monteiro da Silva (1983) fala em mais de cem membros. Nasce então o Centro Eclético Fluente Luz Universal Raimundo Irineu Serra (Cefluris). ${ }^{8}$

O grupo liderado por Padrinho Sebastião agregou outras influências ao Santo Daime, como por exemplo a inserção de elementos culturais da umbanda na cosmologia e ritualística. Mas a inovação que marcou, de forma polêmica, a história dessa instituição religiosa foi a adoção ritual e cotidiana da Cannabis ${ }^{9}$

7 Fabiano Kaxinawá teria afirmado a um repórter que fora seu avô - o pajé Sueiro Huni Kuin - que teria apresentado o nixi pae (a denominação da ayahuasca para os Huni Kuin) para Mestre Irineu; Benki Piyanko, da etnia ashaninka, também teria afirmado em reportagem que seu avô Samuel teria dado ayahuasca pela primeira vez a Mestre Irineu, sendo inclusive citado no hino "Papai Samuel" (cf. Labate; Coutinho, 2014, p. 232-233). Durante minha pesquisa de campo, coletei outros dados nesse sentido: Hundu Shawa, da etnia arara-jaminawa, afirmou-me (em entrevista realizada em junho de 2016) que seu bisavô Crispim teria dado ayahuasca para Mestre Irineu, e que este teria tido iniciações com xamãs de diversas etnias; já Saturnino Brito, expressivo líder daimista, afirmou-me (em entrevista realizada em março de 2016) que Mestre Irineu havia dito algumas vezes que se iniciou na ayahuasca em apenas uma tribo indígena, mas que jamais disse em qual teria sido.

8 Em 1998 o Cefluris foi renomeado de Igreja do Culto Eclético da Fluente Luz Universal (Iceflu), mas é o antigo nome que é usado correntemente entre os adeptos.

9 Forma abreviada de Cannabis sativa, usada em substituição a "maconha", que possui uma carga pejorativa perante a sociedade mais ampla. 
pelos adeptos. Lucio Mortimer (2000), ex-hippie que se tornou um dos principais seguidores de Padrinho Sebastião, narra que após sua conversão ao Santo Daime na década de 1970, ele continuou usando a Cannabis escondido por pouco tempo, e quando decidiu contar a Sebastião Mota, este já tinha sido avisado em sonho por seres espirituais. Lucio ficou surpreso quando o líder da comunidade lhe contara do sonho e pedira algumas mudas para experimentação. ${ }^{10}$ Depois desse episódio a Cannabis foi tendo seu uso ressignificado por este grupo religioso, tendo sido santificada e nomeada de Santa Maria. A Cannabis passou a ser chamada também de "pito", tendo além da sacralidade um caráter íntimo que relaxa e relativiza a impessoalidade, uma planta santa e íntima (Groisman, 1999, p. 103).

Geralmente a Cannabis é usada nos intervalos ou ao fim das cerimônias daimistas, muitas vezes para abrandar a força do daime. "A Santa Maria, usada depois do Santo Daime, pode propiciar uma sensação de desobstrução, propiciando visões; agindo também como alentadora em momentos difíceis durante uma 'viagem'” (MacRae, 2005, p. 472). Também é usada no cotidiano, sendo de primordial importância na cosmologia dessa vertente religiosa. Atualmente a Cannabis é utilizada por grande parte dos daimistas do Cefluris, cotidianamente e em alguns poucos rituais em que ela é usada junto com o daime. No entanto, essa instituição religiosa não reconhece oficialmente o uso dessa planta, principalmente devido à sua ilegalidade em território brasileiro. Há igrejas ceflurianas em que o consumo é generalizado, há outras que o consumo é ameno e discreto, e há aquelas em que consumir é expressamente proibido, variando conforme a opção espiritual e pessoal do dirigente.

Pelo fato de os adeptos admitirem o consumo de Cannabis, o Cefluris se tornou a instituição mais estigmatizada no campo religioso ayahuasqueiro. Por outro lado, foi a que mais se expandiu para outras localidades do mundo. Atualmente há notícia de rituais daimistas em 43 países, em todos os continentes habitados, tornando-se uma religião transnacional (Assis; Labate, 2014). De um único centro na região periférica de Rio Branco, o Santo Daime se transformou

10 A história narrada por Mortimer (2000) em seu livro, e que também é reproduzida pela oralidade, assume características místicas, no sentido proposto por Eliade (1972), do mesmo modo que ocorre o encontro de Mestre Irineu com a ayahuasca, e se torna o mito fundador da religião, conforme demonstra Goulart (1996). 
numa imensa rede mundial que varia entre o institucional e o informal, com milhares de adeptos.

Em trabalho empolgante publicado recentemente, Assis e Labate (2014) apresentam duas "características estruturais" do Cefluris: a miscibilidade e a psicoatividade. O conceito de miscibilidade aparece pela primeira vez na clássica obra Casa-grande e senzala (Freyre, 2006) para designar a capacidade dos portugueses de se "misturar" com outras culturas, e serviu para explicar como um reino tão pequeno conseguiu se expandir tanto. A miscibilidade, segundo Assis e Labate (2014, p. 15), dota o Santo Daime de uma aptidão "de se misturar a outras religiosidades e incorporar elementos delas em sua cosmologia e prática ritual" e "torna-o teologicamente poroso e passível de ser adaptado a diferentes culturas, localidades e concepções religiosas, permitindo formas variadas de arranjos e bricolagem de crenças" (Assis; Labate, 2014, p. 16).

Já a psicoatividade, para Assis e Labate (2014, p. 15-16), "remete ao protagonismo que o uso ritual de substâncias psicoativas apresenta no âmago desse grupo desde seu nascimento", principalmente o daime, mas também a Santa Maria e mais recentemente o rapé e kambô, ${ }^{11}$ entre outras. O consumo ritual dos psicoativos confere ao Santo Daime uma estreita relação com o xamanismo, como se pode observar na literatura antropológica: para Monteiro da Silva (1983), o Santo Daime estaria marcado por transes xamânicos individuais e coletivos, mesmo que nem todos os comungantes estejam no estágio do Mestre Irineu, Padrinho Sebastião e outros; Fróes (1986) coloca a religião daimista como um tipo de xamanismo, afirmando que Mestre Irineu e Padrinho Sebastião são "xamãs"; para Couto (1989), o Santo Daime seria um "xamanismo coletivo", e todos os adeptos seriam "xamãs em potencial"; a assertiva de Couto é sustentada na obra de MacRae (1992), que aponta ser este um aspecto democrático da religião daimista; Dias Jr. (1992) acredita na "iniciação xamânica" de Mestre Irineu e Padrinho Sebastião; Groisman (1999) argumenta que o Santo Daime não seria um sistema xamânico de conhecimento, mas que existiria nessa religião uma práxis xamânica em um contexto cultural cristão. Scuro (2016) aponta o Santo Daime como uma tradição de neoxamanismo. Leo Artese, neoxamã que relatarei adiante, considera

11 Como veremos em outros momentos do texto, os rapés são pós macerados, geralmente com tabaco combinado a outras substâncias, que são assoprados nas narinas. Já o kambô é a secreção da rã Phyllomedusa bicolor, conhecida como "vacina do sapo". 
o Santo Daime como o xamanismo brasileiro mais completo (cf. Labate, 2004, p. 456). Não apenas os pesquisadores relacionam o Santo Daime ao xamanismo, mas também os próprios adeptos. $O$ fato de o consumo da ayahuasca ser o elemento central dos rituais aproxima essa religião da práxis xamânica.

\section{Neoxamanismo}

Labate (2004) postulou a categoria neoayahuasqueiros, que indica sujeitos cujas práticas são novas modalidades de consumo da Ayahuasca nos centros urbanos. O surgimento dos neoayahuasqueiros seria um desdobramento do processo de expansão das religiões ayahuasqueiras para as grandes metrópoles do país (Labate, 2004, p. 66). São vários os contextos dos novos usos da ayahuasca nas cidades, que Labate $(2004$, p. 31) elencou em sua pesquisa:

[...] uso da ayahuasca por grupos de teatro; ayahuasca com meditações do Osho (Rajneesh); ayahuasca para recuperação de moradores de rua; ayahuasca para músicos; ayahuasca para a realização de terapias corporais; ayahuasca em consultórios terapêuticos; vivências ou terapias coletivas com ayahuasca; uso da ayahuasca dentro do candomblé; ayahuasca ligada à terapia de florais; neoxamanismo dentro do CEFLURIS e neoxamanismo com outras plantas alteradoras dos estados de consciência.

Assim, podemos visualizar arranjos de neoxamanismo (Oliveira, 2012; Labate, 2004) ou xamanismo urbano (Magnani, 1999b, 2005). Neoxamanismos seriam "[...] novos modelos de espiritualidade, terapia, consumo e sociabilidade, em que a 'tradição' torna-se um recurso simbólico e retórico fundamental" (Oliveira, 2012, p. 32). Diferentemente dos xamanismos dos povos indígenas, largamente descritos em textos antropológicos, “[...] o dito xamanismo urbano não é uma atualização, modernização ou transposição, para a sociedade ocidental, dessas práticas indígenas. É outra coisa, uma nova construção, em cujo processo de elaboração entram elementos e traços tanto do referencial indígena como de outras vertentes." (Magnani, 2005, p. 222). Para Magnani (1999a, 1999b, 2005), o xamanismo urbano estaria inserido na lógica e circuito mais geral da Nova Era; seus praticantes seriam sujeitos integrados ao circuito neoesotérico.

A notável plasticidade do neoxamanismo impede qualquer tipo de padronização, e os ritos e aspectos cosmológicos acabam por obedecer à idiossincrasia 
de cada dirigente ou grupo. Todavia, é possível observar tendências. No circuito urbano da ayahuasca, tornou-se comum um modelo de ritual em que as medicinas da floresta (ayahuasca e rapé, entre outras) são consumidas, são entoados cânticos de inspiração indígena, do complexo Nova Era, ou mesmo hinos do Santo Daime, são tocados instrumentos orgânicos, como tambores e maracás, são escutados cânticos e mantras em som sintético, geralmente com o grupo em volta de uma fogueira, cada qual sentado ou deitado em seu colchonete. As influências culturais na organização e execução desses rituais são diversas, mas a ênfase comumente recai no arsenal simbólico de origem indígena.

Labate (2004), ao conceituar de "neoxamãs" os praticantes de neoxamanismo, afirmou que são indivíduos modernos que se tradicionalizam. Frequentemente são indivíduos oriundos da classe média urbana que se lançam em iniciações xamânicas em aldeias indígenas da floresta amazônica, no Santo Daime da região acriana, com vegetalistas peruanos, ou com indígenas mexicanos e norte-americanos. É claro que quase ninguém se intitula neoxamã ou xamã urbano, haja vista que esses termos não possuem o mesmo capital e poder simbólico (Bourdieu, 2012) que o termo xamã. Muitos se autodenominam de xamanistas, praticantes de xamanismo.

\section{Xamanismo pano}

As etnias do tronco linguístico pano habitam regiões da floresta amazônica da Bolívia, Peru e Brasil. Em território brasileiro existem 17 povos pano, numa população estimada em 10 mil indivíduos, no Acre, Amazônia e Rondônia. Trata-se das seguintes etnias: apolima-arára, jamináwa, náwa, nukiní, poyanáwa, jamináwa-arara, kontanáwa, shanenáwa, shawandáwa, katukína, kaxinawá, kaxararí, korúbo, marúbo, matís, matsés, yawanawa (Abreu, 2008, p. 112). Várias dessas etnias fazem o uso de ayahuasca e outras substâncias em seu complexo cultural xamânico desde tempos imemoriais, em especial os Kaxinawá/Huni Kuin ${ }^{12}$ (Meneses, no prelo) e os Yawanawa (Oliveira, 2012). Chamo aqui, arbitrariamente, de xamanismo pano, o complexo cultural xamânico praticado por alguma das etnias do tronco pano, seja no contexto das aldeias, seja no circuito urbano da ayahuasca.

12 Os dois nomes referem-se à mesma etnia. 
Um aspecto interessante a ser assinalado é a estreita relação que algumas dessas etnias possuem com o Santo Daime, haja vista que a grande parte das etnias pano se encontram no Acre, mesmo estado em que o Santo Daime se formou e se desenvolveu. Segundo relatos contidos nos trabalhos de Meneses (no prelo) e Oliveira (2012), a tradição xamânica entre os Kaxinawá e Yawanawa estava quase se perdendo, seja pelo alcoolismo deliberado dentro das aldeias, seja pela atuação dos missionários evangélicos. Há indícios (Ginzburg, 1990) que após contato de alguns indígenas com igrejas daimistas, a ayahuasca passou a ser revalorizada nas aldeias. ${ }^{13}$ Se o Santo Daime acabou sendo importante no processo de revitalização do complexo xamânico em algumas aldeias, também é possível afirmar que esse contato gerou trocas culturais que influenciaram a ambos: os daimistas passaram a consumir as medicinas da floresta para além da ayahuasca, ao passo que muitos indígenas passaram a se fardar no Santo Daime e a consumir Santa Maria (Fernandes, no prelo).

Guilherme Meneses, alicerçado nos relatos de seus interlocutores e nas suas observações em campo, afirma que há um processo de transformação nos rituais Kaxinawá/Huni Kuin (uma das etnias mais conhecidas do tronco pano). O antropólogo assim descreve:

Houve, assim, neste novo tempo [xinã bena], ou Nova Era, uma grande transformação na forma de tomar o nixi pae nas aldeias do Humaitá. Desde quando era tomado esporadicamente, geralmente no escuro e deitado na rede, em silêncio ou com cantos à capela e com a presença majoritária de homens adultos ou velhos huni kuĩ, passou-se a se reunir frequentemente, sentados no chão (ou em cadeiras), com a presença de homens, mulheres e crianças (e eventualmente de nawás e outros povos), tanto no shubuã (casa comunal), como no chamado "terreirão" (espaço externo). Hoje, durante as sessões de nixi pae, também há apresentações da "cultura", katxanawa, danças (da jiboia, da tartaruga etc.), defumação, uso de outras medicinas (rapé, sananga, kambô etc.) e presença de instrumentos como violão, maracá e tambores; geralmente na segunda parte dos trabalhos, em que se cantam canções em português/hãtxa kuin recebidas pelos próprios huni kuĩ

13 Essa é uma hipótese que necessita de um aprofundado trabalho de campo (etnográfico e de história oral) para ser efetivamente confirmada, mas os trabalhos de Meneses (no prelo), Oliveira (2012) e Carvalho (2013) apontam, em alguns momentos, nesse sentido. 
provenientes de diversas terras indígenas, além de cantos de outros povos indígenas e de outras linhas de trabalhos espirituais. (Meneses, no prelo, p. 11).

Podemos afirmar que o xamanismo pano se apresenta na contemporaneidade em formatos muito mais híbridos, agregando elementos de outros complexos culturais, e inseridos em redes e circuitos, onde são efetivadas alianças com outros segmentos espirituais, em especial o neoxamanismo e o Santo Daime. Ninawá, liderança huni kuin, fala de uma "Nova Era indígena", com ênfase no desenvolvimento da espiritualidade e da cultura, um verdadeiro movimento de transformação desde o ano 2000 (cf. Meneses, no prelo). Creio que tal movimento iniciou-se quando os atores indígenas entraram no circuito urbano da ayahuasca. Labate e Coutinho (2014, p. 219) certificam que os pioneiros na entrada ao universo ayahuasqueiro urbano são Leopardo e Fabiano Kaxinawá, filhos de Siã Kaxinawá, a liderança mais reconhecida de seu povo. Os Huni Kuin iniciaram esse processo em meados dos anos 2000, e desde então indígenas de outras etnias passaram também a realizar rituais nos centros urbanos fora da Amazônia. Atualmente, os Yawanawa dividem com os Huni Kuin o protagonismo indígena nos circuitos xamânicos contemporâneos.

Se neoxamãs são indivíduos da classe média urbana que se tradicionalizam, os indígenas que angariam valores típicos da vida urbana e se "modernizam" são categorizados por Labate (2004) de neonativos. Os rituais do que classifiquei aqui de xamanismo pano geralmente são chamados de pajelança, e os indígenas são apresentados nos circuitos como pajés ${ }^{14}$ mesmo que não possuam o mesmo status dentro das aldeias.

\section{As medicinas da floresta}

A categoria psicoatividade, que Assis e Labate (2014) utilizaram para se referir ao Cefluris (Santo Daime), adéqua-se para os outros segmentos presentes no circuito xamânico contemporâneo. Os adeptos realizam um uso espiritual

14 Pajé seria o “possuidor do poder” (Kracke, 1992 apud Langdon, 1996, p. 27). Na literatura antropológica, equivale ao termo xamã (Langdon, 1996). 
de substâncias psicoativas que são vistas como plantas de poder ${ }^{15}$ ou enteógenos, ${ }^{16}$ dentre elas as medicinas da floresta. Estas seriam as substâncias utilizadas pelas etnias do tronco pano que acabaram se popularizando entre os daimistas e xamanistas: ayahuasca, rapés, sananga e kambô. A ayahuasca é a principal. Nixi pae é o pai, o chefe das medicinas, segundo Parã Kaxinawá, liderança das mulheres na aldeia Boa Vista, Terra Indígena do Rio Humaitá (AC) (cf. Meneses, no prelo). Essa característica de protagonismo da ayahuasca também é sobremaneira percebida nos hinos daimistas.

Os rapés são tabaco macerado com outras plantas de propriedades psicoativas. São assoprados nas narinas por instrumentos individuais em forma de "V", chamados de kuripe, ealongados para que uma pessoa assopre na outra narina, chamados de tepi. Há especificidades nos usos do rapé nas aldeias, nas cidades, nos diferentes segmentos; no entanto, podemos dizer que os rapés podem ser consumidos durante e no intervalo dos rituais, e no cotidiano. Os rapés são usados para a cura física ou espiritual, para trazer vigor, claridade no pensamento, ou simplesmente para limpar as narinas. Muitas vezes manifestam efeitos purgativos, como o vômito, principalmente se a pessoa estiver também na força da ayahuasca.

A sananga, chamada de "colírio da floresta", é um líquido feito com diferentes espécies de plantas. ${ }^{17}$ Assim como o rapé, é utilizada durante ou no intervalo dos rituais, assim como no cotidiano. No entanto, não é tão difundida quanto os rapés, e um número menor de pessoas consomem. Segundo Hundu Shawan,

15 A expressão plantas de poder é bastante usada pelos adeptos inseridos nos circuitos xamânicos, talvez por influência do universo Nova Era ou mesmo de uma literatura específica, que engloba, entre outros, os livros de Carlos Castañeda. Essa denominação indica que tais plantas transmitem poder e conhecimento espiritual.

16 O termo enteógeno vem do grego e foi cunhado por Gordon Wasson em 1969 (Labate; Goulart; Carneiro, 2005, p. 31). Pode significar "aquilo que produz uma inspiração ou possessão divina" (Labate; Goulart; Carneiro, 2005, p. 31) ou "aquilo que leva alguém a ter o divino dentro de si" (MacRae, 1992, p. 16). O termo enteógeno é evocado por grande parte dos daimistas e xamanistas, sempre em oposição a alucinógeno.

17 Labate e Coutinho (2014) apontam a sananga como sendo Tabernaemontana undulata. No entanto, Hundu Shawan, da etnia jaminawa-arara, afirmou-me (em entrevista realizada em fevereiro de 2016) que a sananga pode ser feita com diferentes plantas. Há também um vídeo no portal YouTube (https://www.youtube.com/watch?v=JKEMMCmC5EU) que demonstra a sananga sendo feita por uma daimista, com a raiz da planta Petiveria alliacea, conhecida popularmente como "guiné". 
essa medicina serve para caçar, para aumentar a "miração" da ayahuasca, para curar possíveis enfermidades nos olhos. Alguns não indígenas usam sananga para tratar problemas nos olhos, como catarata. Essa substância é conhecida pela sua exacerbada ardência nos olhos durante a aplicação.

Outra importante medicina da floresta é o kambô (secreção da rã arbórea Phyllomedusa bicolor), conhecido como veneno do sapo, ou vacina do sapo. Segundo Lima e Labate (2008, p. 331), está ocorrendo uma espécie de "xama nização"/"esoterização"/"terapeutização" do kambô nos centros urbanos; este parece estar sendo apresentado como análogo a uma "planta de poder". No entanto, entre as etnias indígenas que o usam, é tido como um remédio especial, capaz de eliminar o cansaço, a sonolência, a preguiça etc. (Lima; Labate, 2008, p. 316). Ao contrário do que ocorre nas cidades, nas aldeias o kambô é aplicado por qualquer indivíduo, desde que este seja considerado pelos outros como possuidor de qualidades morais. A aplicação não é restrita apenas aos xamãs, e geralmente os mais requisitados são os caçadores bem-sucedidos (Lima; Labate, 2008, p. 327). Entre os ayahuasqueiros nas cidades, a legitimidade pra aplicação do kambô geralmente é restrita aos neoxamãs e principalmente aos próprios indígenas tidos como pajés.

A capacidade curativa é a principal característica do kambô. Entre os Katukina (tronco pano) ele sempre é utilizado nas primeiras horas de manhã. Já entre os daimistas ou xamanistas, nem sempre essa premissa é acatada. O kambô muitas vezes é consumido não oficialmente, ${ }^{18}$ sem vínculo com rituais, em pequenos grupos que se articulam. Nessas ocasiões podem ser usados rapés e sanangas, haja vista que essas substâncias têm mais facilidade de fazer parte do cotidiano. O kambô também é comumente utilizado ao final dos rituais (neo)xamânicos ou daimistas. Ele nunca é usado no decorrer do ritual, pois segundo alguns indígenas com quem travei contato, ele não pode ser aplicado sob o efeito da ayahuasca.

Outras substâncias também são consumidas pelos atores desses circuitos, sempre com intuito espiritual e evocando a prerrogativa da cura. Algumas inclusive chegam a ser classificadas, por alguns adeptos, como medicina

18 O uso não oficial se dá pelo fato de que a divulgação do kambô foi proibida através de uma portaria da Anvisa em 2004. Há uma tensão que envolve kambô e biopirataria por grupos estrangeiros (cf. Lima; Labate, 2008). 
da floresta mesmo não tendo a floresta amazônica como origem. A Cannabis, chamada de pito ou Santa Maria, tão substancial na cosmologia daimista, passou a ser consumida também por indígenas e xamanistas. A planta é geradora de bastante polêmica devido a sua ilegalidade, grande parte dos adeptos não usam, e há aqueles que recriminam ou toleram mas não apoiam o uso. Falar sobre ela muitas vezes é um tabu. Com raras exceções, é regra os adeptos pedirem segredo ou ao menos discrição em relação à sociedade mais ampla. Isso complica uma escrita etnográfica nos moldes de contextualização das circunstâncias da pesquisa (Clifford, 2011), haja vista que os interlocutores quase sempre não permitem que se aborde esse assunto. De todo modo, podemos afirmar que a Cannabis é uma das substâncias bastante presentes nos circuitos xamânicos contemporâneos, e há aqueles (mesmo que muito poucos) que a consideram também como uma medicina da floresta.

Pode-se observar, em especial entre os xamanistas, o uso do tabaco sagrado durante os rituais, que são baforados nos cachimbos, sem tragar. A jurema (Mimosa hostilis), bebida utilizada por índios no Nordeste e em religiões afro-brasileiras (Grünewald, 2005; Mota, 2005), é raramente consumida nos rituais em que se consomem as medicinas, tanto por ser uma prática recente quanto pela dificuldade em se obter a bebida, mas é classificada como uma medicina da floresta por alguns atores. Outro uso não comum é o de cogumelos psicotrópicos. Alguns adeptos consomem cogumelo, geralmente o Psilocybe cubensis, eventualmente em sessões informais. Há grupos de neoxamanismo do Caminho Vermelho ${ }^{19}$ que consomem cogumelos (não pude confirmar qual espécie) no mesmo ritual em que se consome ayahuasca. Também entre esse grupo se consome peiote em rituais próprios, no México e nos EUA. Ainda menos comum é a incidência do cacto San Pedro/wachuma ${ }^{20}$ (Echinopsis pachanoi)e da tchanga. ${ }^{21}$

19 Vertente neoxamânica cuja inspiração principal são as etnias mexicanas e norte-americanas. O Caminho Vermelho possui extensões em várias localidades do mundo.

20 O cacto San Pedro, também conhecido como wachuma, é usado desde tempos imemoriais por culturas andinas, e na contemporaneidade psiconautas (Labate, 2004) e xamanistas se interessam pelo seu uso.

21 A tchanga é uma mistura de cristais de jurema (que possui DMT) com ervas, que são fumadas. Vem sendo bastante utilizada em festivais de música eletrônica. Recentemente passou a ser utilizada por alguns adeptos dos circuitos xamânicos contemporâneos. Ainda não foi publicado nenhum texto acadêmico em língua portuguesa sobre a tchanga, o que demanda pesquisas futuras. 


\section{Rituais (neo)xamânicos}

A legitimidade do neoxamã ou neonativo provém da sua força espiritual, do seu poder de cura, da eficácia do seu ritual, dos seus dons musicais, etc., ou seja, performaticamente. É claro que ser indígena muitas vezes é um critério de legitimidade no campo ayahuasqueiro, todavia diversos neoxamãs possuem mais prestígio nesse campo que os neonativos. Uma performance ritual bem executada pode trazer uma série de benefícios para todo o grupo, ao passo que, se mal executada, pode gerar infortúnios. Nesse sentido, os atores confeccionam elaborados rituais, que, apesar das idiossincrasias, possuem uma estrutura comum: o consumo das medicinas da floresta, animados por cânticos ao redor da fogueira.

Os neonativos geralmente denominam seus rituais de pajelança, ou especificam como ritual tradicional de sua etnia. ${ }^{22}$ Para o já mencionado Leopardo Kaxinawá, "as pajelanças são trabalhos de cura individuais, com as medicinas, com as plantas, com o rezo, pela conexão com a ancestralidade. Os pajés são anciões ou pessoas mais velhas, que têm esse papel da pajelança." ${ }^{23}$ Durante os rituais, sob o efeito das medicinas, os pajés fazem o rezo e cantam em língua nativa. Há também cânticos bem característicos em português, acompanhados de violões, assim como danças coletivas, como a "dança da jiboia". Alguns indígenas agregam versões de hinos daimistas, mas nem todos julgam isso como algo positivo, como o próprio Leopardo, que considera ser "uma mistura de linhas diferentes", o que acaba influenciando a cultura e tradição huni kuin.

Quando realizados por neoxamãs, os rituais recebem outras nomenclaturas. Vamos aos exemplos etnográficos. Elves do Juruá, nativo do estado do Acre, afirma não poder fazer pajelança, pois não é pajé e nem domina a língua indígena. Elves se considera "caboclo", procedente de uma mistura, pois seu avô era pertencente à etnia puyanawa, e sua avó era branca. ${ }^{24}$ Ele então preferiu adotar o nome caboclança, e posteriormente caboclança universal, pois passou

22 Lembro-me que o neonativo Hundu Shawan, no primeiro ritual dele de que participei, em fevereiro de 2016, afirmou-me com todo gabarito "que ele não faz qualquer coisa como estão fazendo por aí, mas sim ritual tradicional shawan kuin".

23 Entrevista realizada em setembro de 2016.

24 Podemos dizer que Elves está na fronteira entre neoxamã e neonativo. 
a agregar elementos culturais e musicais de diversas tradições espirituais. Elves e alguns familiares são fardados no Santo Daime.

Outro caso de caboclança é efetuado por Ronaldo Mendonça, na cidade de Bauru, interior de São Paulo. Ele é mestre de yoga (além de terapeuta e mestre de reiki) e tem profunda ligação com tradições orientais, e acaba trazendo elementos diversos para compor seu ritual com as medicinas. Ele denomina seu trabalho de caboclança oriental, e une a "linha dos caboclos" (que envolve a umbanda, a linhagem dos pajés, os cantos nativos, etc.) com a "linha oriental" (linhagem do tantra yoga, Shiva, Buda, etc). Considera sua empreitada como pertencente à Nova Era, pois agrega noções vindas de diversas tradições espirituais, esotéricas, etc. Ronaldo é fardado no Santo Daime, canta seus hinos daimistas durante a sessão; seu hinário chama-se Serpente de Luz e tem um perfil diversificado, que traduz bem seu trabalho de caboclança. Diferentemente dos outros atores sociais aqui descritos, Ronaldo "trabalha na linha de incorporação", isto é, abre espaço para manifestações de "entidades espirituais" e faz atendimentos. Denomina informalmente seu recinto ritualístico de "terreiro de desenvolvimento".

Um dos atores sociais mais prestigiosos desse circuito é o neoxamã Leo Artese. Ele é dirigente do Céu da Lua Cheia, uma notável igreja daimista na cidade de São Paulo. É também um dos principais articuladores da cultura (neo)xamânica no Brasil, sendo proprietário do portal www.xamanismo.com.br e presidente da Associação Brasileira de Xamanismo - instituição fundada em 2009 como resultado do I Encontro Brasileiro de Xamanismo. Sobre sua formação, Leo declarou-me: "Tive iniciações com um Shipibo (Mateo Arevalo) da Comunidade San Francisco de Pucallpa, com um homem-medicina da reserva Rosebud Lakota, que era conhecido como Standing Coyote, e outros amigos que apareceram no caminho, Cherokee, Melvin, Navajo, e até o próprio Leopardo [Kaxinawá]."25 Leo codificou o ritual do Voo da Águia, com as medicinas, e dá cursos de xamanismo, tendo escrito dois livros sobre o tema. Ele ressalta que faz adaptações inspiradas das práticas que aprendeu (Labate, 2004, p. 453). Segundo Matricciani (2013, p. 26), o Voo da Águia teve origem em 1992, e desde então vem sendo tecida uma arquitetura cerimonial que reúne conhecimentos do xamanismo andino, nativos norte-americanos e pajelança brasileira.

25 Entrevista realizada em março de 2014. 
Outro caso a ser citado é o Voo do Beija-Flor, de Ronaldo Pereira. Este é morador do Céu do Mapiá (sede do Cefluris) e é um violeiro renomado no circuito daimista. Nasceu no Santo Daime, se considera veterano na religião, mas somente nos últimos dez anos "entrou em contato com outros segmentos do xamanismo". Conheceu o cacique Xerê, da etnia katukina, e com ele aprendeu sobre as medicinas, em especial o kambô. Depois conheceu Leo Artese, e foi durante uma sessão do Voo da Águia que Ronaldo idealizou o Voo do Beija-Flor. É um ritual musicado com hinos daimistas, na temática do Beija-Flor. Ele afirma que é um "trabalho sem doutrinação, ele não traz essa pregação dos índios americanos, do Vento Norte, do Vento Sul, não sei o que do Espírito, mas deixa você trabalhar o seu íntimo, focado no Beija-Flor, neste mistério". O daimista engendra uma crítica: "Quando entrei nesse mundo do xamanismo, vi que é um xamanismo urbano, essa galera que conduz não estão nem aí pra floresta e pra natureza. Então o Voo do Beija-Flor traz essa mensagem, traz esse recado, convida as pessoas pra floresta." Transcrevo aqui um trecho significativo de sua fala, sobre a legitimidade do xamã:

Quando eu idealizei o Voo do Beija-Flor, envolvido no xamanismo, eu tenho que me preparar, estudar um pouco sobre xamanismo e tal, fiquei naquela preocupação mas fiz o primeiro. O Leo Artese até me convidou pra participar de uns eventos lá que capacita, né, depois pensei, o que que é um xamã? O xamã nasce xamã, né, ninguém vira xamã depois, o cara pode até exercer ali aquela função, desenvolver seus dons. Então eu fiquei vendo, eu nasci no Santo Daime, tenho quase 40 anos de conhecimento com a planta ayahuasca que é o centro do xamanismo aqui no nosso Brasil, América do Sul. Então eu falei, ah, vou esquecer essa coisa de xamã, se for pra ver o lado xamã, eu tomo daime desde que nasci, então tá, pratico a espiritualidade, faço trabalhos de cura desde que nasci, participo de cerimônias, então posso ser um xamã, se eu quiser ser um xamã, eu sou um xamã naturalmente. ${ }^{26}$

Podemos mencionar ainda o neoxamã Fabiano Carneiro, cujo nome iniciático é Akaiê Sramana. Ele é fundador da Terra Xamã, uma instituição que oferece diversos cursos e serviços, e possui características de uma empresa. É dirigente

26 Entrevista realizada em agosto de 2016. 
do centro xamânico Aldeia de Shiva, e realiza rituais de (neo)xamanismo. Escreveu alguns livros sobre o tema, e se mantém presente no ambiente virtual. Afirmou-me ${ }^{27}$ ter sido iniciado pelos Kaxinawá, pelos Aymaras do lago Titicaca, na Bolívia, pelos Navajos do Grand Canyon, nos EUA, e pelos Jhankris do Nepal. Através dos ensinamentos dos índios kaxinawá, confeccionou a cerimônia Voo do Gavião-Real, onde apresenta "a sabedoria cultural e espiritual do simbolismo do Gavião-Real". Akaiê advoga para si uma descendência indígena: sua mãe seria descendente dos Caramuru Tupinambá.

Recentemente passaram a existir rituais daimistas nos quais são estabelecidos momentos para o uso das medicinas (rapé e sananga). Como se pode ver, estamos em um território repleto de (re)invenção de tradições, onde elementos culturais de diversas culturas são mesclados, reelaborados, ressignificados. Seja na pajelança, caboclança ou voo xamânico, culturas xamânicas ancestrais se unem ao universo Nova Era, dando origem a novos arranjos rituais. A agência dos atores é evidente tanto na elaboração quanto na performance dos rituais. O protagonismo recai sobre atores não humanos: as próprias medicinas da floresta. A divulgação dos rituais acontece no ambiente virtual ou no "boca a boca". O preço ${ }^{28}$ para participar dos rituais varia de 50 a 200 reais, podendo alcançar cifras maiores quando realizados no exterior.

\section{Redes, circuitos e atores}

"O conceito de cultura na antropologia simbólica é centrado no ator e, consequentemente, a cultura emerge através da ação" (Langdon, 1996, p. 24). Através da agência de atores xamanistas, assistimos à confecção de uma "cultura xamânica" na contemporaneidade cujas características principais consistem: na adoção de "cosmologias universalistas" que valorizam e agregam elementos simbólicos de culturas nativas de variados contextos históricos e geográficos, assim como agregam conhecimento erudito ocidental, como textos acadêmicos ou espíritas/esotéricos; na experiência performática com plantas psicoativas,

27 Em entrevista realizada em maio de 2017.

28 Ao invés de preço ou ingresso, utiliza-se com frequência as expressões "energia de troca" ou "investimento". 
das quais a "força espiritual" e capacidade de curar proporcionam aos adeptos a adesão a um particular estilo de vida, onde utilizar as medicinas da floresta nos rituais e no cotidiano é a própria "busca espiritual"; na composição de redes e circuitos nacionais e internacionais, de ambitude xamânica, por onde circulam indivíduos, substâncias, saberes, tradições. ${ }^{29}$

A coexistência do xamanismo pano, neoxamanismo e Santo Daime é evidenciada por Oliveira (2012) como o novo campo xamânico. Essas vertentes se organizam através de circuitos, ${ }^{30}$ e por isso considero também apropriada a expressão "circuitos xamânicos contemporâneos". Percebi, no decorrer do trabalho de campo, que os circuitos são construídos através de alianças e colaborações, onde prevalece a amizade. Todavia, também observei conflitos e acusações mútuas.

Sobre o processo de transnacionalização religiosa, podemos pensar nos fluxos e redes (Oro et al., 2012). As redes transnacionais que se formam em torno de pessoas constituem-se em instituições religiosas abertas, semiformalizadas, que funcionam através de parcerias, que se apoiam na cumplicidade entre agentes, e cujos líderes geralmente sustentam sua legitimação no carisma pessoal. Essas redes personalizadas associam-se a outras redes, cruzando-se entre e si, e sobrepõem-se umas às outras. Nas redes de relações, observam-se a aliança e a colaboração, mas também investidas de competição, inimizade, acusações mútuas. O poder e o reconhecimento social dos atores estão diferentemente distribuídos, configurando relações assimétricas entre eles.

Conceituam-se como atores "nodais" aqueles com mais alto nível de reconhecimento e poder, cujo carisma pessoal os torna referências para os outros atores da rede. Os atores "eixos" estão em nível logo abaixo, pois possuem certo prestígio, e mantêm estreitas relações com os atores "nodais". E em terceiro lugar estão os atores "secundários", que são líderes de igrejas locais,

29 É desses (neo)xamanismos que me proponho a tratar aqui, pois foram neles que realizei trabalho de campo. Todavia, reconheço as abundantes possibilidades de xamanismos pelo mundo, e a diversidade de abordagens dos estudiosos sobre tais xamanismos.

30 Magnani (1999a) desenvolve o conceito de circuito na sua obra sobre o movimento neoesotérico na cidade de São Paulo. Se para o autor os pontos do circuito neoesotérico são os centros especializados, as livrarias, os consultórios de terapeutas, etc., nos circuitos xamânicos contemporâneos os pontos são os centros xamânicos, as igrejas e comunidades daimistas, as aldeias indígenas no Acre, etc. 
que possuem relações mais próximas com os atores "eixos" e mais distanciadas com os "nodais" (Oro et al., 2012, p. 10). A conceituação dos atores depende da delimitação das redes. A título de exemplo, pensando apenas as redes xamânicas, Leo Artese pode ser considerado um ator "nodal"; no entanto, se considerarmos a rede daimista do Cefluris, Leo Artese é um ator "eixo", e Alfredo Gregório, dirigente geral dessa instituição, o ator "nodal".

Vamos aos exemplos. A igreja daimista Céu do Patriarca, localizada em Florianópolis, pode fornecer dados pra subsidiar a argumentação. Ela é filiada ao Cefluris, e cumpre todo o calendário daimista. Possui alianças com os Huni Kuin e os Yawanawa, e regularmente há eventos de xamanismo pano. Alguns indígenas se fardaram na igreja, como é o caso do pajé Kuni descrito por Oliveira (2012). Também há aliança com o segmento neoxamânico Caminho Vermelho, que realiza uma série de eventos no local. Vários daimistas dessa igreja também são filiados ao Caminho Vermelho. De frente ao salão onde se realizam os rituais, tem uma tenda de temascal ou "tenda do suor", que remete a tradições xamânicas norte-americanas. ${ }^{31}$

No Acre, desde o ano 2000, ocorre o Encontro para o Novo Horizonte, na sede da instituição daimista Cefli, comandada por Luis Mendes do Nascimento e seu filho Saturnino Brito. O evento ocorre sempre de 30 de dezembro a aproximadamente 10 de janeiro, e nesse período há vários trabalhos daimistas. Esse encontro, a cada ano, reúne mais pessoas (de 250 a 400), grande parte vinda dos centros urbanos do sul e sudeste do Brasil, e também de outros países. Segundo Saturnino, a partir de 2010, indígenas de várias etnias passaram a frequentar 0 encontro. As medicinas da floresta se popularizaram entre os adeptos, ao passo que muitos indígenas se tornaram daimistas..$^{32}$ Durante os rituais, há os indígenas que usam cocares, pintam os corpos, etc., e há os indígenas fardados que utilizam a indumentária da religião daimista. Esse diálogo entre indígenas e não indígenas no circuito daimista vem se intensificando com o passar dos anos.

31 Sobre a tenda do suor, ver Braga (2010).

32 Saturnino informou-me, em uma entrevista realizada em março de 2017, sobre a criação de uma igreja daimista, nos moldes do Cefli, em uma aldeia huni kuin, na região de Tarauacá, às margens do rio Muru. Labate e Coutinho (2014) citam o caso da igreja daimista na terra indígena Apurinã, nos moldes do Cefluris. O indígena conhecido como Tuim Nova Era afirma ter realizado trabalhos daimistas em terra indígena huni kuin, e que isso teria auxiliado no processo de revitalização da "cultura espiritual" de seu povo (cf. Meneses, no prelo). 
Nos EUA, ${ }^{33}$ há diversas igrejas daimistas. Uma delas, o Céu da Águia Branca, tem relação com o Céu do Mar (cuja dirigente é Nonata, filha de Padrinho Sebastião) e com a etnia yawanawa. ${ }^{34}$ Nonata faz trabalho de "iluminação de sofredores", que perpassa pelas tradições daimista, de umbanda e espiritismo popular, e depois aplica rapé, sananga e kambô (indígenas). Essa mesma igreja daimista estadunidense é também um local da Native American Church (NAC), que seria uma espécie de neoxamanismo, onde se consome peiote. Índios norte-americanos frequentam a NAC, e um deles é fardado no Santo Daime. Eu poderia trazer outros exemplos, mas o que pretendo demonstrar é a composição rizomática dessas redes: um rizoma de múltiplas entradas, onde qualquer ponto pode ser conectado a qualquer outro (Deleuze; Guatarri, 2011).

\section{Considerações finais}

Ao pensar em xamanismo, é preciso considerá-lo como um complexo sociocultural (Langdon, 1996, p. 26), que se expressa numa enorme heterogeneidade de arranjos possíveis. No circuito urbano da ayahuasca, atores de diferentes segmentos xamânicos efetivam alianças entre si, o que aproxima os adeptos, que muitas vezes pertencem a mais de uma vertente. As cosmologias e os arsenais ritualísticos se entrecruzam.

Tendo a ayahuasca como fio condutor, passamos por uma série de rituais (pajelança, caboclança, voo xamânico) onde outras substâncias também são consumidas para além da bebida amazônica: são as chamadas medicinas da floresta. Nesse território recheado de (re)invenção de tradições, os atores depositam no consumo espiritual de substâncias psicoativas a centralidade de seus rituais. O protagonismo desses rituais recai nos atores não humanos: ayahuasca, rapés, sananga, kambô, entre outros..$^{35}$

33 Os dados sobre os EUA foram coletados com o norte-americano Justin Guy (residente em Nova Iorque) em um feitio ocorrido em Campo Grande, em abril de 2016.

34 Existe uma aliança espiritual entre os dirigentes e membros da igreja carioca Céu do Mar com membros da etnia yawanawa, inclusive com casamento de filhos de ambas as lideranças.

35 Devido à dimensão do presente texto, não foi possível assinalar como se dá o protagonismo das substâncias psicoativas nos rituais, intento este que ficará para futuras análises. 
Nos circuitos xamânicos contemporâneos, ou novo campo xamânico, onde coexistem tradições espirituais diversas, nota-se a circulação de indivíduos, substâncias, saberes e tradições. Com exemplos etnográficos, o intento foi demonstrar a composição rizomática dessas redes.

\section{Referências}

ABREU, P. S. R. de. Diversidade linguística brasileira: as línguas páno e suas características ergativas. 2008. Dissertação (Mestrado em Letras e Linguística)-Faculdade de Letras, Universidade Federal de Goiás, Goiânia, 2008.

ALMEIDA, M. Prefácio. In: LABATE, B. C. A reinvenção do uso da ayahuasca nos centros urbanos. Campinas: Mercado de Letras, 2004. p. 13-24.

ANTUNES, H. F. A literatura antropológica e a reconstituição histórica do uso da ayahuasca no Brasil. R@u: Revista de Antropologia da UFSCar, São Carlos, v. 3, n. 2, p. 76-103, 2011.

ASSIS, G.; LABATE, B. Dos igarapés da Amazônia para o outro lado do Atlântico: a expansão e internacionalização do Santo Daime no contexto religioso global. Religião e Sociedade, Rio de Janeiro, v. 34, n. 2, p. 11-35, 2014.

BOURDIEU, P. O poder simbólico. Rio de Janeiro: Bertrand Brasil, 2012.

BRAGA, K. R. G. Modelando xamãs: o caso da tenda do suor. 2010. Dissertação (Mestrado em Antropologia Social)-Centro de Ciências Humanas, Letras e Artes, Universidade Federal do Rio Grande do Norte, Natal, 2010.

CARDOSO DE OLIVEIRA, R. O trabalho do antropólogo. São Paulo: Ed. Unesp, 2006.

CARVALHO, M. B. de. Articulações para o desenvolvimento na floresta: populações locais e políticas públicas em torno da natureza na microrregião de Cruzeiro do Sul, Acre. 2013. Tese (Doutorado em Antropologia Social)-Instituto de Filosofia e Ciências Humanas, Universidade Estadual de Campinas, Campinas, 2013.

CLIFFORD, J. A experiência etnográfica: antropologia e literatura no século XX. Rio de Janeiro: Ed. da UFRJ, 2011.

COUTO, F. de L. R. Santos examãs: estudos do uso ritualizado da ayahuasca por caboclos da Amazônia, e, em particular, no que concerne sua utilização sócio-terapêutica na doutrina do Santo Daime. 1989. Dissertação (Mestrado em Antropologia Social)Departamento de Antropologia, Universidade de Brasília, Brasília, 1989.

DELEUZE, G.; GUATARRI, F. Mil platôs: vol. 1. São Paulo: Editora 34, 2011. 
DIAS Jr., W. O império de Juramidam nas batalhas do astral: uma cartografia do imaginário no culto do Santo Daime. 1992. Dissertação (Mestrado em Antropologia)-Pontifícia Universidade Católica de São Paulo, São Paulo, 1992.

ELIADE, M. Mito e realidade. São Paulo: Perspectiva, 1972.

FERNANDES, S. C. Esquece que é macumba: a macumba nos escritos acadêmicos e a diversidade das religiões afro-brasileiras. 2015. Dissertação (Mestrado em Antropologia)-Faculdade de Ciências Humanas, Universidade Federal da Grande Dourados, Dourados, 2015.

FERNANDES, S. C. As medicinas da floresta: o consumo ritual de psicoativos no circuito do Santo Daime. In: LABATE, B.; GOULART, S. O uso de plantas psicoativas nas Américas. Campinas: Mercado de Letras. No prelo.

FREYRE, G. Casa-grande e senzala. São Paulo: Global, 2006.

FRÓES, V. Santo Daime, cultura amazônica: história do povo juramidam. Manaus: Suframa, 1986.

GEERTZ, C. A interpretação das culturas. Rio de Janeiro: LTC, 2008.

GINZBURG, C. Mitos, emblemas, sinais: morfologia e história. São Paulo: Companhia de Letras, 1990.

GOLDMAN, M. Alguma antropologia. Rio de Janeiro: Relume Dumará, 1999.

GOULART, S. As raízes culturais do Santo Daime. Dissertação (Mestrado em Antropologia Social)-Faculdade de Filosofia, Letras e Ciências Humanas, Universidade de São Paulo, São Paulo, 1996.

GROISMAN, A. Eu venho da floresta: um estudo sobre o contexto simbólico do uso do Santo Daime. Florianópolis: UFSC, 1999.

GRÜNEWALD, R. Sujeitos da Jurema e o resgate da "ciência do índio". In: LABATE, B.; GOULART, S. (Org.). O uso ritual das plantas de poder. Campinas: Mercado de Letras, 2005. p. 239-277.

GUIMARÃES, M. B. L.A“Lua Branca” de Seu Tupinambá e de Mestre Irineu: estudo de caso de um terreiro de umbanda. 1992. Dissertação (Mestrado em Ciências Sociais)-Instituto de Filosofia e Ciências Sociais, Universidade Federal do Rio de Janeiro, Rio de Janeiro, 1992.

LABATE, B. C. A reinvenção do uso da ayahuasca nos centros urbanos. Campinas: Mercado de Letras, 2004.

LABATE, B. C. Dimensões legais, éticas e políticas da expansão do consumo da ayahuasca. In: LABATE, B.; GOULART, S. (Org.). O uso ritual das plantas de poder. Campinas: Mercado de Letras, 2005. p. 397-457. 
LABATE, B. C.; COUTINHO, T. O meu avô deu a ayahuasca para o Mestre Irineu: reflexões sobre a entrada dos índios no circuito urbano de consumo de ayahuasca no Brasil. Revista de Antropologia, São Paulo, v. 57, n. 2, p. 215-250, 2014.

LABATE, B. C.; GOULART, S.; CARNEIRO, H. Introdução. In: LABATE, B.; GOULART, S. (Org.). O uso ritual das plantas de poder. Campinas: Mercado de Letras, 2005. p. 29-55.

LANGDON, E. J. M. Introdução: xamanismo - velhas e novas perspectivas. In: LANGDON, E. J. M. (Org.). Xamanismo no Brasil: novas perspectivas. Florianópolis: Editora da UFSC, 1996. p. 9-37.

LIMA, E.; LABATE, B. A expansão urbana do kampo (Phyllomedusa bicolor): notas etnográficas. In: LABATE, B. et al. (Org.). Drogas e cultura: novas perspectivas. Salvador: EDUFBA, 2008. p. 315-344.

LUNA, L. E. Vegetalismo: shamanism among the mestizo population of Peruvian Amazon. Stockholm: Almqvist \& Wikisell International, 1986.

MacRAE, E. Guiado pela lua: xamanismo e uso ritual da ayahuasca no culto do Santo Daime. São Paulo: Brasiliense, 1992.

MacRAE, E. Santo Daime e Santa Maria: usos religiosos de substâncias psicoativas lícitas e ilícitas. In: LABATE, B.; GOULART, S. (Org.). O uso ritual das plantas de poder. Campinas: Mercado de Letras, 2005. p. 459-485.

MAGNANI, J. Mystica urbe: um estudo antropológico sobre o circuito neo-esotérico na cidade. São Paulo: Studio Nobel, 1999a.

MAGNANI, J. O xamanismo urbano e a religiosidade contemporânea. Religião e Sociedade, Rio de Janeiro, v. 20, n. 2, p. 113-140, 1999b.

MAGNANI, J. Xamãs na cidade. Revista USP, São Paulo, n. 67, p. 218-227, 2005.

MATRICCIANI, F. Xamanismo universal: o voo da águia. 2013. Trabalho de Conclusão de Curso (Bacharelado em Psicologia)-Universidade Anhanguera Educacional, Osasco, 2013.

MENESES, G. Navegando no astral: fluxos e transformações nos rituais de nixi pae. In: LABATE, B.; GOULART, S. O uso de plantas psicoativas nas Américas. Campinas: Mercado de Letras. No prelo.

MONTEIRO DA SILVA, C. O Palácio de Juramidam - Santo Daime: um ritual de transcendência e despoluição. 1983. Dissertação (Mestrado em Antropologia Cultural)Instituto de Ciências Humanas, Universidade Federal de Pernambuco, Recife, 1983.

MOREIRA, P.; MacRAE, E. Eu venho de longe: Mestre Irineu e seus companheiros. Salvador: EDUFBA, 2011. 
MORTIMER, L. Bença Padrinho!. São Paulo: Céu de Maria, 2000.

MOTA, C. N. da. Jurema e identidades: um ensaio sobre a diáspora de uma planta. In: LABATE, B.; GOULART, S. (Org.). O uso ritual das plantas de poder. Campinas: Mercado de Letras, 2005. p. 219-237.

OLIVEIRA, A. F. Yawa-nawa: alianças e pajés nas cidades. 2012. Dissertação (Mestrado em Antropologia Social)-Centro de Filosofia e Ciências Humanas, Universidade Federal de Santa Catarina, Florianópolis, 2012.

ORO, A. P. et al. (Org.). Transnacionalização religiosa: fluxos e redes. São Paulo: Terceiro Nome, 2012.

SCURO, J. Neochamanismo en América Latina: una cartografía desde el Uruguay. 2016. Tese (Doutorado em Antropologia Social)-Instituto de Filosofia e Ciências Humanas, Universidade Federal do Rio Grande do Sul, Porto Alegre, 2016.

SOARES, L. E. O rigor da indisciplina: ensaios de antropologia interpretativa. Rio de Janeiro: Relume-Dumará, 1994.

WEBER, M. Economia e sociedade. Brasília: UnB, 1991. 